Provided for non-commercial research and education use. Not for reproduction, distribution or commercial use.

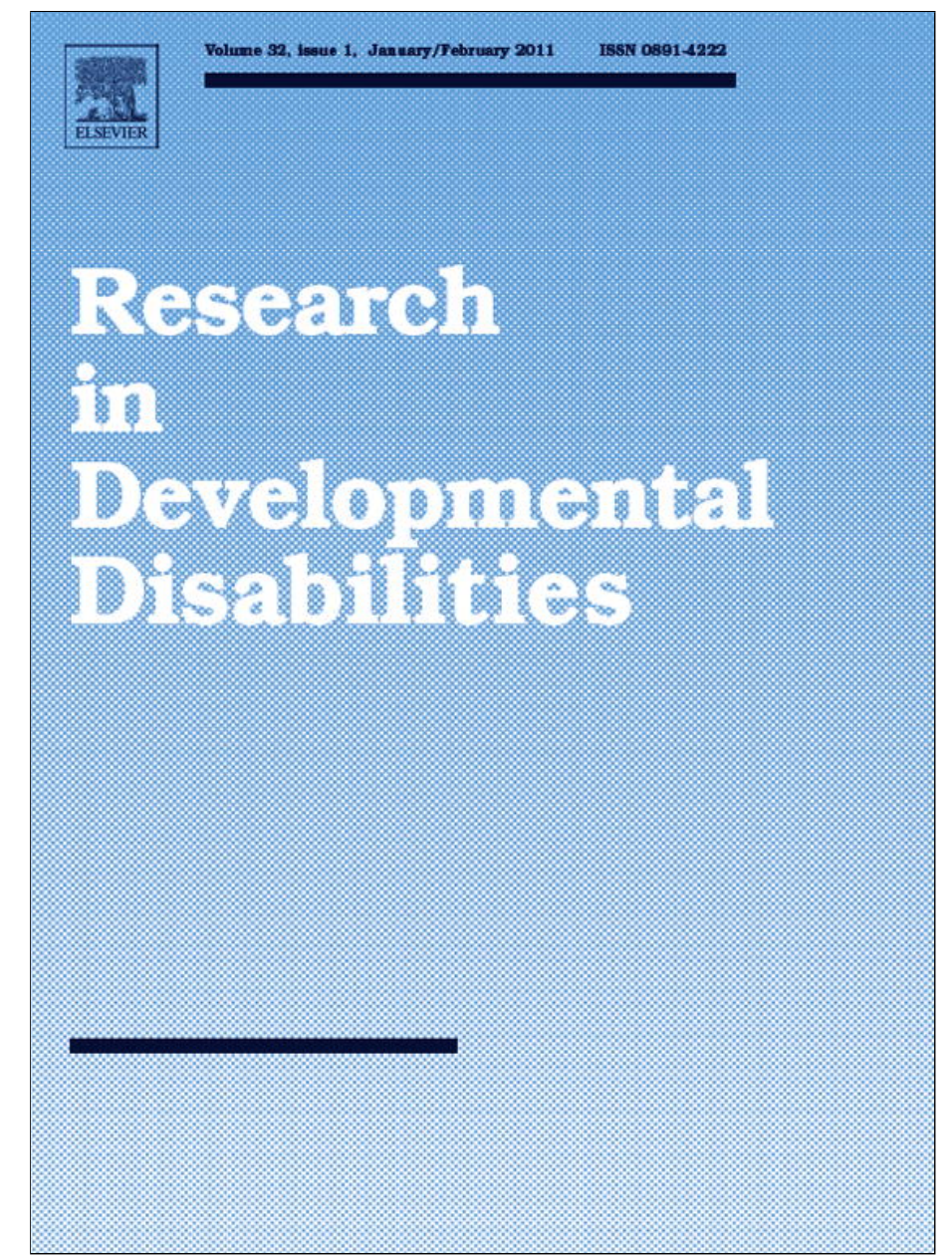

(This is a sample cover image for this issue. The actual cover is not yet available at this time.)

This article appeared in a journal published by Elsevier. The attached copy is furnished to the author for internal non-commercial research and education use, including for instruction at the authors institution and sharing with colleagues.

Other uses, including reproduction and distribution, or selling or licensing copies, or posting to personal, institutional or third party websites are prohibited.

In most cases authors are permitted to post their version of the article (e.g. in Word or Tex form) to their personal website or institutional repository. Authors requiring further information regarding Elsevier's archiving and manuscript policies are encouraged to visit:

http://www.elsevier.com/copyright 


\title{
Parent-infant interaction in infant siblings at risk of autism
}

\author{
Ming Wai Wan ${ }^{\mathrm{a}, *}$, Jonathan Green ${ }^{\mathrm{a}}$, Mayada Elsabbagh ${ }^{\mathrm{b}}$, Mark Johnson ${ }^{\mathrm{b}}$, Tony Charman ${ }^{\mathrm{c}}$, \\ Faye Plummer ${ }^{\mathrm{a}}$ \\ the BASIS Team ${ }^{1}$ \\ ${ }^{a}$ Community Based Medicine, University of Manchester, United Kingdom \\ ${ }^{\mathrm{b}}$ Centre for Brain and Cognitive Development, Birkbeck, University of London, United Kingdom \\ ${ }^{\mathrm{c}}$ Institute of Education, University of London, United Kingdom
}

\section{A R T I C L E I N F O}

\section{Article history:}

Received 7 September 2011

Received in revised form 15 December 2011

Accepted 15 December 2011

Available online

\section{Keywords:}

Autism siblings

Mother-child relations

High-risk infants

Parent sensitivity

\begin{abstract}
A B S T R A C T
Recent models of the early emergence of autism spectrum disorder (ASD) propose an interaction between risk susceptibility and the infant's social environment, resulting in a progressively atypical developmental trajectory. The infant's early social environmental experience consists mostly of interaction with caregivers, yet there has been little systematic study of early parent-infant interaction in infants at risk of ASD. This study examined the global characteristics of parent-infant interaction in 6- to 10-month-old infants with an older sibling diagnosed with ASD (at-risk sibs), in comparison with a group of infants with no family history of ASD (low-risk sibs). As part of the British Autism Study of Infant Siblings (BASIS), 6-min videotaped unstructured play interactions of motherinfant dyads (45 at-risk sibs and 47 low-risk sibs) were rated on global aspects of parentinfant interaction, blind to participant information. Differences in global characteristics of interaction were observed in both infant and parent contributions in the at-risk group compared to low-risk controls. In analyses adjusted for age and developmental level, atrisk sib infants were less lively, and their parents showed higher directiveness, and lower sensitive responding (as a trend after adjustment). Level of infant liveliness was independent of other interactive behaviour. Consistent with reports in previous literature in older children with autism and in other neurodevelopmental disorders, our findings may suggest that infants at genetic risk are exposed to a more directive interactive style relatively early in infancy. We discuss possible explanations for these findings and implications for further developmental study and intervention.
\end{abstract}

(C) 2012 Published by Elsevier Ltd.

\section{Introduction}

In recent years, prospective studies have made important advances in delineating social information processing and communication atypicalities in infants at risk of autism spectrum disorder (ASD) and, increasingly, those who go on to be diagnosed (e.g. Cassel et al., 2007; Goldberg et al., 2005; Rozga et al., 2011; Stone, McMahon, Yoder, \& Walden, 2007). Other behavioural 'markers' in infancy have also been shown to predict later ASD (Landa \& Garrett-Mayer, 2006; Landa,

\footnotetext{
* Corresponding author. Tel.: +44 1612750731.

E-mail address: m.w.wan@manchester.ac.uk (M.W. Wan).

$1{ }^{*}$ The BASIS team in alphabetical order: Simon Baron-Cohen, Patrick Bolton, Rachael Bedford, Susie Chandler, Janice Fernandes, Holly Garwood, Kristelle Hudry, Teodora Gliga, Leslie Tucker, and Agnes Volein.
} 
Holman, \& Garett-Mayer, 2007; Mitchell et al., 2006; Zwaigenbaum et al., 2005). The early emergence of social and other behavioural atypicalities might suggest that perturbations in caregiver-infant interaction are a salient feature in the developmental trajectories of infants at risk of ASD. Unlike the measurement of social functioning per se, caregiver-infant interaction sees each participant influencing the other's behaviour bi-directionally, shaping the social dynamic over time and, in turn, infant social competence. Early atypicalities in social communication may disrupt caregiver response and dyadic mutuality which, over time, may amplify early susceptibilities into an increasingly atypical social developmental trajectory (Dawson, 2008; Elsabbagh \& Johnson, 2007, 2010). Evidence for this transactional view of development is well established in neurotypical development, in which patterns of parent-child interaction form early and help shape the child's ongoing social and communicative development (Feldman \& Greenbaum, 1997; NICHD Early Child Care Research Network, 2001; Pastor, 1981).

Studies show that parents of older children already diagnosed with ASD tend to use more directive play interaction, for example, involving more high intensity behaviours, non-verbal prompts, and high physical proximity, compared with controls (e.g. Doussard-Roosevelt, Joe, Bazhenova, \& Porges, 2003; Lemanek, Stone, \& Fishel, 1993; Nassan El-Ghoroury \& Romanczyk, 1999). One inference is that, in attempting to encourage 'desirable' social behaviour, some parents are inadvertently drawn into increasingly directive interactions. In neurotypical development, a directive style of parental interaction in effect discourages the infant from engaging with the parent (e.g. Lussier, Crimmins, \& Alberti, 1994). Higher parent directiveness is also reported to be more common in mothers of infants with other kinds of neurodevelopmental atypicality, such as Down syndrome, and is associated with reduced behaviours or developmental progress in infants (Cielinski, Vaughn, Seifer, \& Contreras, 1995; Landry \& Chapieski, 1989; Slomins \& McConachie, 2006). This transactional or 'interactive specialisation' model suggests that such interaction perturbation might have particular salience in the early development of infants at risk for ASD because (i) the social nature of ASD may mean that infants at risk are particularly dependent on the intactness of the dyadic social communication system (i.e. there is a specific riskdiathesis); and (ii) that social brain development in ASD may be particularly environment-dependent thus differentially sensitive to the effects of social interaction. This effect could work both ways, making at-risk infants particularly vulnerable to poor social input but also particularly sensitive to its improvement. Longitudinal evidence from children diagnosed with autism, for instance, shows that interactive synchrony with parents predicts child communication outcomes (Siller \& Sigman, 2002, 2008), and specific enhancement of parental communicative synchrony following targeted parent-mediated intervention is associated with significantly improved child communication within the dyad (Green et al., 2010).

However, there has been little observational study of caregiver-infant interaction in the context of emerging ASD and associated atypicalities in infancy. Retrospective studies of parents' home videos have identified a range of social and communicative differences between infants who later develop ASD from those who do not (Clifford \& Dissanayake, 2008; Esposito \& Venuti, 2009; Osterling \& Dawson, 1994), which may be associated with later social communicative functioning (Poon, Watson, Baranek, \& Poe, 2011). One recent study, however, focused on parent-infant interaction specifically in the home videos of a small sample who went on to develop ASD compared with a typically developing and an intellectual disability group. Infants who later developed ASD demonstrated lower social orientation at six months and a smaller increase thereafter that tended to be passive (Saint-Georges et al., 2011). Their caregivers stimulated them for longer (compared with typically developing controls) but appeared to withdraw after the first year. Parental solicitation of response through touch remained high whereas through gestures was low throughout, which may suggest an increasing tendency for caregivers to favour more directive forms of engagement, perhaps due to a lack of infant response to other forms. Although the study of home videos show high ecological validity and are not subject to the limitations of caregiver memory, they are biased by what parents choose to videotape or submit for study and may lack comparability due to varied content. Furthermore, this method does not allow for a comparison group of infants who may show similar early behaviours or interactions (on measures determined retrospectively) but who do not develop ASD later on. These issues are overcome by prospectively studying infants who later develop ASD, but such studies have not been feasible in general population samples because of its low prevalence.

One prospective approach established in recent years is to study a group who is known to be at relatively high risk of developing ASD due to its high heritability - later born siblings of children diagnosed with ASD (hereafter, 'at-risk sibs'; Rogers, 2009; Yirmiya \& Charman, 2010). Two studies to date have adopted this approach to investigate caregiver-child interactions in the first year of life. Yirmiya et al. (2006) examined the unstructured play interactions of 21 four-month-old at-risk siblings compared with 21 infants (hereafter, 'low-risk sibs') who had an older typically developing sibling. The total amount of infant-led play did not differ between groups, but within infant-led play itself, a quarter of at-risk sibs showed low synchronous interaction compared to none of the low-risk sibs. One explanation for this finding is that mothers find it difficult to match and respond to their infant's affect and affective change, particularly if at-risk infants show reduced affective expression. Studies using the 'still-face' paradigm (involving face-to-face interaction, followed by the adult becoming unresponsive/neutral then resuming interaction - Tronick, Als, Adamson, Wise, \& Brazelton, 1978) suggest that atrisk infants do tend to remain unusually affectively neutral during unexpected maternal behaviour change (Cassel et al., 2007; Yirmiya et al., 2006, but no difference was reported by Merin, Young, Ozonoff, \& Rogers, 2007). In Yirmiya et al.'s (2006) sample, low-synchrony infant-led interactions were also more common among infants who later had language delays.

More recently, Rozga et al. (2011) studied mother-infant interactions at 6 months in at-risk sibs who later went on to develop ASD $(N=8)$ compared with those who did not $(N=41)$ and with low-risk sibs $(N=35)$. No group differences were 
observed in social smiles, social vocalisations, or other communicative behaviour towards the mother. However, interactions may have been too short to capture interactive differences ( $1 \mathrm{~min}$ in length) and may not reflect naturalistic interaction (with no touching or use of toys). At 12 months, in an enhanced sample, joint attention and requesting behaviour were lower in atrisk sibs who went on to receive an ASD diagnosis, compared with the other groups, but the findings came from structured observation and not parent-infant interaction.

The current cross-sectional study examined parent-infant interactions as part of a larger prospective longitudinal study. Unlike almost all previous study of parent-infant interaction in at-risk sibs - which has been microanalytic, the focus of the current study is on the global characteristics of interaction. While microanalytic measurement provides numeric-rich data on the counts, durations and temporal sequences of clearly defined behaviours and affect, global ratings involve the evaluation of qualitative and quantitative attributes of domains of interaction along a scale, often taking into account contextual information. As discussed, microanalytic study has identified specific at-risk sib differences in affective synchrony in infant-led play (Yirmiya et al., 2006), infant social orientation, and maternal use of touch to elicit response (Saint-Georges et al., 2011). However, the possible impact of such differences on overall quality of dyadic interaction is unclear; for example, is the higher frequency of maternal touch to obtain attention affectionate or intrusive? Moreover, parent-mediated intervention tends to be implemented at a 'macro' level. Interaction studies in neurotypical development comparing 'micro' and 'macro' approaches suggest that the two approaches are complementary. Measures that are conceptually very similar using each approach are poorly correlated and might tap relatively different constructs that hold independent explanatory value in predicting future functioning (Feldman \& Greenbaum, 1997; Mesman, 2010). However, one study of global interaction examined maternal sensitivity at 18 months in mothers of at-risk toddlers and found no differences between those who were subsequently diagnosed with ASD $(n=12)$ and those who were not $(n=21)$ (Baker, Lyons, Messinger, \& Grantz, 2010). The child's interactive behaviour was not investigated.

The aim of the current study was to examine the global aspects of interaction in at-risk sib using a larger sample than previous interaction studies. Based on previous studies on parent-child interaction in children with ASD and in at-risk infants, our objectives were to investigate whether, compared with the low-risk group, parents of at-risk siblings were less sensitively responsive and more directive, the infants were less interactive (less attentive to parent, less positive in affect, and less lively), and the dyadic atmosphere less mutual and less intense in engagement.

\section{Method}

\subsection{Sample}

One hundred and four parent-infant dyads were recruited sequentially into the national British Autism Study of Infant Siblings (BASIS): 54 at-risk infants (21 male, 33 female) and 50 low-risk infants (21 male, 29 female). The infants were seen when they were $6-10$ months of age (mean $=238.3$ days, $S D=37.2$ ). The study had ethical approval from the London Research Ethics Committee (ref: 09/H0718/14). Informed consent was obtained from one or both parents. At enrolment, none of the infants had been diagnosed with any medical or developmental condition. At-risk sib status was defined by having an older sibling (hereafter, 'proband') with a community clinical diagnosis of ASD (or in 4 cases, a half-sibling). Infants may have other older siblings. Proband diagnosis was confirmed by two expert clinicians (PB, TC) based on information using the Development and Wellbeing Assessment (DAWBA; Goodman, Ford, Richards, Gatward, \& Meltzer, 2000) and the parent-report Social Communication Questionnaire (SCQ; Rutter, Bailey, \& Lord, 2003). Most probands met criteria for ASD on both the DAWBA and SCQ $(n=44)$. While a small number scored below threshold on the SCQ $(n=4)$, no exclusions were made due to meeting threshold on the DAWBA and expert opinion. For 2 probands, data were only available for either the DAWBA $(n=1)$ or the SCQ $(n=1)$. For 4 probands, neither measure was available (aside from parent-confirmed local clinical ASD diagnosis at intake). Parent-reported family medical histories were examined for significant medical conditions in the proband or extended family's members, with no exclusions made on this basis.

Infants in the low-risk group were recruited separately from a volunteer database at the Birkbeck Centre for Brain and Cognitive Development. Inclusion criteria included full-term birth, normal birth weight, and lack of any ASD within firstdegree family members (as confirmed through parent interview regarding family medical history). All low-risk infants had at least one older-sibling (in 5 cases, only half-sibling/s). Screening for possible ASD in these older siblings was undertaken using the SCQ with no child scoring above instrument cut-off.

Of 104 dyads recruited, data from 12 were excluded from the current study because interaction tapes were not collected $(n=4)$ or due to technical problems (no clip or too brief: $n=3$; no sound: $n=5$ ). The final sample comprised 45 at-risk infants (20 male, $44.4 \%$; mean age $=7.16$ months $[S D=1.2]$ ) and 47 comparison low-risk infants $(18$ male; $47.4 \%$; mean age $=7.36$ months $[S D=1.2])$. All parents who took part in the interaction were mothers.

Of the available data from families in the at-risk group and based on the occupation of the highest social status adult, 19 (42\%) were in professional/managerial occupations, 4 (9\%) in technical, support, skilled trades, and non-manual occupations, and 4 (9\%) in semi-skilled/unskilled occupations ( 1 (2\%) student/unemployed; 17 (36\%) missing). Of the families of low-risk infants, 28 (57\%) were professional/managerial, 15 were technical, support skilled trades and non-manual (32\%), 3 were in semi-skilled/unskilled occupations (6\%) and 1 (2\%) was a student/unemployed. 


\subsection{Measures}

\subsubsection{Caregiver-infant interaction}

A measure of global caregiver infant unstructured play interaction was developed from the modification of existing validated measures (Murray, Fiori-Cowley, Hooper, \& Cooper, 1996; Blazey, Leadbitter, Holt, \& Green, 2008). The purpose of modification was to suit our study's age range and to focus on global features of interaction that may be implicated in the atrisk group and in ASD, and which may have consequences for infant social development. All scales were refined through extensive pilot coding. The final measure rated interaction along a 1 (lowest) to 7 (highest) scale in 7 domains, including 2 parent scales (sensitive responsiveness and non-directiveness), 3 infant scales (attentiveness to parent, positive affect, and liveliness), and 2 dyadic scales (mutuality and intensity of engagement). The concepts of dyadic mutuality and parent sensitive responsiveness were taken from the Coding of Attachment-Related Parenting in Autism (CARP-A; Blazey et al., 2008), with the scales modified to suit infancy. The CARP-A is a validated modification for autism of the original CARP(Matias, 2006). The remaining 5 scales originate from parts of the Global Rating Scales (Murray et al., 1996), which have been validated and used in infants in other risk samples (e.g. of high social adversity) and were adapted for use in our older age range. Since infant attachment was not the current focus, the low end of the 'attentiveness to parent' scale did not measure actively avoidant behaviours exclusively but rather low attentiveness to the parent more generally, which may be passive or avoidant. A brief description of these scales is given in the Appendix and the full rating scheme manual is available on request.

\subsubsection{Mullen Scales of Early Learning (MSEL)}

A standardised test of early cognitive and motor development validated for use in infants of 0-68 months was included in the present study. The MSEL consists of measures of receptive and expressive language, visual reception and gross and fine motor skills. Combined visual reception and fine motor skills raw scores were used as a control for infant non-verbal developmental level, since developmental delay had shown effects on interaction in other studies (e.g. Cielinski et al., 1995).

\subsection{Procedure}

An episode of unstructured play interaction was video recorded with the parent-infant dyad sat on a floor mat in a room, following a period of familiarisation. The parent was instructed to engage in play using a set of toys if he/she so wished, as she would do at home. The section of video clip rated was the first $6 \mathrm{~min}$ at the point from when the researchers left the room. Clips were rated independently, blind to all participant information. Inter-rater agreement was tested by the independent blind coding of $25 \%$ of the study sample video clips. Using single measures intraclass correlation (two-way mixed effects model using an absolute agreement definition), moderate to high agreement (all $p<0.001$ ) was demonstrated in all domains: maternal sensitivity: $r=0.66$; maternal non-directiveness: $r=0.63$; infant attentiveness to parent: $r=0.58$; infant positive affect: $r=0.82$; infant liveliness: $r=0.66$; mutuality: $r=0.80$; engagement intensity: $r=0.68$. Any disagreements in the complete sample were resolved by both raters re-reviewing the clips to reach consensus. During the same visit, the MSEL was conducted by a trained researcher using a testing protocol that was flexible and infant-led.

\subsection{Data analysis}

To examine the characteristics of the modified scales of parent-infant interaction, we studied the internal features of parent-infant interaction in the at-risk group and the comparison low-risk group using partial correlations, adjusting for infant age and non-verbal developmental level. Exploratory factor analysis was performed across the whole cohort with Mplus version 6.1 using maximum likelihood estimation and varimax rotation (an orthogonal rotation). Interaction differences between sibling groups were calculated with one-way ANOVA and then adjusted with ANCOVA, including infant age and non-verbal developmental level as covariates. Due to the theoretical and clinical implications of low parent-infant interaction ratings in typical development, we used chi-squared tests to examine whether low ratings (1-2) were more highly represented in the at-risk group than in the low-risk group.

\section{Results}

\subsection{Descriptive analysis}

No sibling group differences were found in: Maternal age (years: at-risk sib mean $=36.98$ [SD = 36.98]; low-risk sib mean $=36.40[S D=36.40] ; F=0.71$ ), infant age (months: at-risk sib mean=7.16 [SD=1.17]; low-risk sib mean =7.36 $[S D=1.19] ; F=0.71$ ), or infant gender (male at-risk sibs: $n=20$ [44.40\%]; male low-risk sibs: $n=18$ [47.40\%]; $\chi^{2}=0.36$ ). However, at-risk sibs were more likely to have $>1$ sibling $(n=27 ; 60.0 \%)$ than low-risk sibs $\left(n=14 ; 29.8 \% ; \chi^{2}=8.49\right.$; $p<0.004)$.

Scores on the scales of parent-infant interaction were normally distributed. Interaction scores showed no differences with infant gender, maternal age, socioeconomic status or non-verbal development. However, infant age was correlated, after controlling for infant non-verbal development, with parent sensitive responsiveness $(r=0.33 ; p=0.001)$, parent nondirectiveness $(r=0.26 ; p=0.01)$, infant positive affect $(r=0.27 ; p=0.01)$ and infant liveliness $(r=0.39 ; p<0.001)$. 
Subsequent analyses were adjusted for infant age. Infants with $>1$ older sibling showed more intense engagement than those with 1 sibling $(F=4.42 ; p=0.04)$; no other interaction differences with sibling status emerged. This effect disappeared when re-analysed within each group. The MSEL was completed for all but one (at-risk) sib, for which missing data was imputed. Sib groups differed significantly in their non-verbal developmental level score (at-risk sibs: mean $=22.80$; $S D=3.53$; low-risk sibs: mean $=20.80 ; S D=4.33 ; F=5.84 ; p=0.02)$; subsequent analyses were adjusted for infant non-verbal development.

\subsection{Internal characteristics of the global ratings scales}

Cronbach's alpha for the seven interaction scales across the cohort was 0.844 . Patterns of intercorrelation between scales were similar across both sibling groups (Table 1), with the one exception of a positive association between infant positive affect and infant attentiveness to parent found in the at-risk but not the low-risk group. Parent scales were inter-correlated such that lower sensitive responsiveness was accompanied by reduced non-directiveness. Parent sensitive responsiveness (rather than parent non-directiveness) was associated positively with infant attentiveness and infant positive affect. The two dyadic ratings were correlated both to one another and to most other interaction characteristics. In contrast, infant liveliness alone showed no significant correlation with any interaction characteristic in either group.

These correlational findings were supported by an exploratory factor analysis of observed items across the sample. There was a two-factor solution (eigenvalues $>1$, Table 2 ) in which infant and dyadic items together load onto Factor 1 , and parent items load onto Factor 2. Infant liveliness stands alone as not loading on either.

\subsection{Interaction by sibling status}

Group differences in parent-infant interaction were significant in three scales (Table 3). Firstly, at-risk infants showed significantly lower liveliness. Secondly, parents of at-risk infants showed higher directiveness. The significance of both these findings remained after analyses adjusted for infant age and infant non-verbal developmental level. Thirdly, parents of atrisk infants showed lower 'sensitive responding', but this effect was reduced to a non-significant trend $(p=0.08)$ in the adjusted analysis.

The at-risk group contained 9 of the 10 infants (90\%; Fisher exact test: $p=0.007$ ) who showed particularly low liveliness scores (1-2 rating), and 15 of the 17 parents $\left(88 \% ; \chi^{2}=12.90 ; p<0.001\right)$ with particularly low scores $(1-2$ rating) on both

Table 1

Partial correlations of global aspects of interaction controlling for infant age and non-verbal developmental level.

\begin{tabular}{|c|c|c|c|c|c|c|}
\hline & $\begin{array}{l}\text { Parental sensitive } \\
\text { responsive }\end{array}$ & $\begin{array}{l}\text { Parental } \\
\text { non-directiveness }\end{array}$ & $\begin{array}{l}\text { Infant } \\
\text { attentiveness }\end{array}$ & $\begin{array}{l}\text { Infant positive } \\
\text { affect }\end{array}$ & $\begin{array}{l}\text { Infant } \\
\text { liveliness }\end{array}$ & Mutuality \\
\hline \multicolumn{7}{|l|}{ At-risk sibs } \\
\hline Inf centred & $0.67^{* *}$ & & & & & \\
\hline Attentive & $0.58^{* *}$ & 0.21 & & & & \\
\hline Pos affect & $0.57^{* *}$ & 0.22 & $0.62^{* *}$ & & & \\
\hline Liveliness & 0.06 & -0.13 & 0.23 & 0.28 & & \\
\hline Mutuality & $0.78^{* * *}$ & $0.45^{*}$ & $0.85^{* * *}$ & $0.67^{* *}$ & 0.08 & \\
\hline Engaged & $0.54^{* * *}$ & 0.18 & $0.75^{* *}$ & $0.62^{* *}$ & 0.17 & $0.79^{* * *}$ \\
\hline \multicolumn{7}{|l|}{ Low-risk sibs } \\
\hline Inf centred & $0.65^{* *}$ & & & & & \\
\hline Attentive & $0.56^{* *}$ & 0.23 & & & & \\
\hline Pos affect & 0.31 & 0.28 & 0.28 & & & \\
\hline Liveliness & -0.07 & 0.02 & -0.06 & 0.29 & & \\
\hline Mutuality & $0.76^{* *}$ & $0.40^{*}$ & $0.86^{* *}$ & $0.45^{*}$ & 0.01 & \\
\hline Engaged & $0.51^{* *}$ & 0.09 & $0.71^{* *}$ & $0.42^{*}$ & 0.06 & $0.77^{* *}$ \\
\hline
\end{tabular}

Table 2

Exploratory factor analysis rotated factor matrix for parent-infant interaction $(N=104)$.

\begin{tabular}{lll}
\hline & \multicolumn{2}{l}{ Factor } \\
\cline { 2 - 2 } & 1 & 0.493 \\
Parent sensitive responsiveness & 0.063 \\
Parent non-directiveness & 0.857 \\
Infant attentiveness & 0.507 & 0.889 \\
Infant positive affect & 0.088 \\
Infant liveliness & 0.887 \\
Mutuality & 0.830 \\
Engagement intensity & 0.169 \\
\hline
\end{tabular}


Table 3

Global ratings of parent-infant interaction by sibling status.

\begin{tabular}{|c|c|c|c|c|}
\hline & $\begin{array}{l}\text { At-risk sib mean } \\
{[S D](N=45)}\end{array}$ & $\begin{array}{l}\text { Low-risk sib mean } \\
{[S D](N=47)}\end{array}$ & $\begin{array}{l}\text { Unadjusted } F \\
\text { [p value] }\end{array}$ & $\begin{array}{l}\text { Adjusted } F^{\mathrm{a}} \\
{[p \text { value }]}\end{array}$ \\
\hline Parent sensitive responsiveness & $3.23[1.14]$ & $3.79[1.33]$ & $5.13[0.03]$ & $3.12[0.08]$ \\
\hline Parent non-directiveness & $3.05[1.29]$ & $3.91[1.33]$ & $9.64[0.003]$ & $7.10[0.009]$ \\
\hline Infant attentiveness to parent & $3.89[1.32]$ & $3.89[1.39]$ & $0.03[0.86]$ & $0.002[0.97]$ \\
\hline Infant positive affect & $3.98[1.17]$ & $3.79[1.02]$ & $0.54[0.46]$ & $1.02[0.32]$ \\
\hline Infant liveliness & $3.51[1.11]$ & $4.27[1.04]$ & $11.52[0.001]$ & $9.61[0.003]$ \\
\hline Mutuality & $3.05[1.35]$ & $3.17[1.42]$ & $0.26[0.61]$ & $0.04[0.85]$ \\
\hline
\end{tabular}

a Co-varying for infant age and non-verbal developmental level.

sensitive responsiveness (minimally to slightly sensitively responsive) and non-directiveness (highly to very highly directive). Only 2 at-risk dyads received 1-2 ratings in both parent non-directiveness and infant liveliness.

No group differences were found in infant positive affect or infant attentiveness, or in the dyadic scales. As a main effect of number of siblings was found on engagement intensity, engagement intensity was also analysed with number of siblings (1 sibling vs. 2+ siblings) as a second independent variable; no main group effect or interaction emerged.

We investigated further the lack of association between infant liveliness and parent behaviours by testing two post hoc predictions in at-risk sibs regarding possible non-linear relationships: (i) that infants who were in the lowest range of liveliness (ratings 1-2 inclusive) would have parents who were less non-directive (i.e. more directive) than parents of livelier infants; ii) that parents who were in the lowest range for non-directiveness (i.e. more directive; ratings 1-2 inclusive) would have infants who were less lively than those of parents who were less directive. ANOVAs controlling for infant age and infant non-verbal development revealed no significant effect in the former $(F=0.10)$, and a non-significant trend in the latter in the opposite direction from that predicted $(F=2.98 ; p=0.09)$.

\section{Discussion}

This study is the first to demonstrate systematic differences in early global parent-infant interaction between infants at risk of ASD and low-risk controls within a prospective study. Firstly, at-risk sibs showed a stronger tendency toward inactivity, with nine of the ten least lively infants coming from the at-risk group. Somewhat consistent with this finding is the low social initiation reported in Saint-Georges et al.'s (2001) home video study of young infants who were later diagnosed with ASD. In the current study, infant liveliness was not associated with other interaction scales, and our factor analysis suggested it taps a different underlying construct, possibly capturing a trait or temperament difference in at-risk sibs at this age, independent of interaction dynamics. An independent study from our own group also found lower parent-reported motor activity in at-risk compared to low-risk siblings (Leonard, Elsabbagh, Hilla, \& The BASIS team, submitted for publication). Zwaigenbaum et al. (2005) found parent-rated low activity in high-risk siblings at six months that was predictive of ADOS classification of autism at 24 months, and Garon et al. (2009) reported a similar finding in older siblings. Our current findings add to this literature by showing that low activity is captured not only in self-report scales, which are potentially subject to reporting biases, but also in a 6-min blinded observation of caregiver-infant interaction.

Secondly, as predicted, parents of at-risk infants showed interactive behaviours that were more directive and, at trend level, less infant-responsive. A low rating on parent non-directiveness in our study indicates low infant following, acceptance of the infant's experience and/or encouragement of the infant to lead interaction and, notably, more directive, intrusive, and/ or negative behaviours. This interactive style is to be distinguished from the use of directives in maternal speech (which if done sensitively, is not viewed here as directive in the interactive sense) or 'positive structuring' during interaction, which has been shown not to be related to emotional responsiveness in mothers of 18-month olds who go on to develop ASD (Baker et al., 2010). Our findings are consistent with previous reports of increased directiveness (Doussard-Roosevelt et al., 2003) and lower sensitive responding (Blazey et al., 2008) in parents with older children diagnosed with ASD, and with lower sensitive following in infant-led interactions (constituting a key aspect of 'non-directiveness') in mothers of at-risk infant siblings (Yirmiya et al., 2006). Saint-Georges et al.'s (2011) video analysis study also showed higher rates of touching to elicit a response (which may be viewed as directive) in parents of at-risk sibs who were later diagnosed with ASD after 6 months which decreased in other groups. It is possible that infant communicative atypicality results in a perturbation to generic social parent-infant interactive systems in development (Trevarthen \& Aitken, 2001) and that parents then find it relatively difficult to time sensitive responses due to the infant's less functional play and behaviour (Christensen et al., 2010) or nonmeasured developmental difficulties, leading the parent to use a directive style. Although a certain level of parent-led interaction may arguably be adaptive in these contexts (Marfo, 1990), directiveness, as operationalised in the current study, was strongly associated with low sensitive responding in parents and lower mutuality in the dyad and therefore unlikely to be beneficial.

Other potential explanations need to be considered, however. The 'directive' tendency may be an adaptation learned from interacting with the older sibling with ASD. Mothers of at-risk sibs may respond differently to their infant's initiations since 
these may be absent in their older child with ASD. In this context, $60 \%$ of parents in the at-risk group had more than two children, therefore were likely to have had another child without ASD. A more general consideration might be higher levels of parent-related stress experienced by mothers of children with ASD (Hamlyn-Wright, Draghi-Lorenz, \& Ellis, 2007; Kuhn \& Carter, 2006; Tomanik, Harris, \& Hawkins, 2004). Stress might impact on the emotional availability of parents to provide non-directive interaction. As we had no direct measure of parent stress in this study, this remains a consideration for future work. Finally, there is a possible impact of autism symptoms or broader autism phenotype (BAP) in the interacting parent. The BAP consists of subtle social impairments including altered gaze fixation and other face processing differences (Dalton, Nacewicz, Alexander, \& Davidson, 2007), aloofness, rigidity, and diminished social relationships (Piven, Palmer, Jacobi, Childress, \& Arndt, 1997). Family studies suggest a significant prevalence of BAP in families of children with autism, but virtually nothing is currently known about the impact of BAP on parenting. Future studies should consider the possible impact of these characteristics on interaction dynamics.

Potential biases and limitations in the study design need to be considered in the interpretation of these findings. Recruitment into the BASIS project is by self-selection, largely through national advertising direct to families. It is therefore possible that the sample is not fully representative of families with a child with ASD. Against this, the sample is the largest studied to date in this area, interaction ratings were normally distributed and did not vary according to parent and infant characteristics (apart from infant age) on which we had data. Secondly, parents' behaviour is likely to have been altered as a result of their awareness of being videotaped for study. The probable higher anxiety of parents of at-risk sibs must be considered, although their interactions may be taken to represent their behaviour in stressful contexts. Thirdly, while the overall sample is by some way larger then previous work, its size may still be a limitation given the proportion of infants who will later develop ASD. Fourthly, the analysis is cross-sectional and does not allow inference about causal direction. Specifically it is not part of our model to suggest that parental interaction style has any primary causal role in ASD; the developmental impact, if any, of the group differences identified here will need to be ascertained through longitudinal observational studies or the developmental impact of interventions (Green \& Dunn, 2008). Finally, these findings at a macro level will be usefully complemented by further microanalytic interaction study to investigate, for example, the contexts in which the parent is more directive in the two groups and the level of infant engagement that follows.

Although we expect only a minority of the at-risk sibs to develop ASD, the group differences identified here suggest that their early social interaction does show some specifically different characteristics from typical parent-infant interaction at a time well before the earliest behavioural markers of autism risk are generally apparent (Rogers, 2009) or reliably measured (Bryson, Zwaigenbaum, McDermott, Rombough, \& Brian, 2008). This fact suggests important early functional differences in social interaction at this early pre-diagnostic stage of development. In the context of evidence on how early brain neurophysiology (de Haan, Belsky, Reid, Volein, \& Johnson, 2004) and gene expression (Irwin et al., 2000) may respond to altered environmental influence in related contexts, and the recent interest in the possibilities of very early 'preventative' intervention (Dawson, 2008; Wallace \& Rogers, 2010) using social enrichment strategies, these findings are striking. Further study of such group differences will be important in testing current models of emergent autism in development, as well as providing empirically derived targets for intervention strategies.

\section{Acknowledgements}

We are very grateful for the enormous contributions BASIS families have made towards this study. We also thank Richard Emsley for providing statistical advice. The research is supported by the UK Economic and Social Research Council (RES-00022-3525) to M.W. Wan and J. Green; the UK Medical Research Council (G0701484) and the BASIS funding consortium led by Autistica (www.basisnetwork.org) to M.H. Johnson, and by a Leverhulme Early Career Fellowship to M. Elsabbagh.

\section{Appendix}

Description of the global rating scheme of parent-infant interaction.

\begin{tabular}{|c|c|c|}
\hline Domain & Description & Scale extremes \\
\hline \multicolumn{3}{|l|}{ Parental } \\
\hline 1. Sensitive responsiveness & $\begin{array}{l}\text { The identification of, and behavioural response to, infant behaviour } \\
\text { and signals that are contingent and appropriate to meet the infant's } \\
\text { immediate and developmental needs. Responsiveness includes the } \\
\text { appropriate engagement, support and structuring of the infant } \\
\text { when the infant is lacking behaviour }\end{array}$ & $\begin{array}{l}1=\text { Minimally sensitively responsive } \\
7=\text { Very sensitively responsive }\end{array}$ \\
\hline 2. Non-directiveness & $\begin{array}{l}\text { A focus on the infant's experience and agenda as opposed to a } \\
\text { parent-directed focus. A high rating includes non-directive behaviour } \\
\text { that accepts and encourages the infant to lead interaction and } \\
\text { positive comments that reflect the infant's experience. A low rating } \\
\text { includes demanding, intrusive, and negative behaviours and } \\
\text { comments directed at the infant not at the service of promoting } \\
\text { infant-initiated behaviour }\end{array}$ & $\begin{array}{l}1=\text { Highly directive } \\
7=\text { Highly non-directive }\end{array}$ \\
\hline
\end{tabular}


Appendix (Continued)

\begin{tabular}{|c|c|c|}
\hline Domain & Description & Scale extremes \\
\hline \multicolumn{3}{|l|}{ Infant } \\
\hline 4. Attentiveness to parent & $\begin{array}{l}\text { The amount of visual contact with and interest in the parent either directly } \\
\text { (particularly in younger infants) and/or through mutual focus on a third } \\
\text { object (particularly in older infants) as opposed to interest in objects alone } \\
\text { and/or self-absorption. Considerations include infant body/face orientation } \\
\text { toward the parent and (in mutual focus) interest in and acceptance of } \\
\text { objects demonstrated by the parent, and social referencing }\end{array}$ & $\begin{array}{l}1 \text { = Inattentive } \\
7=\text { Very highly attentive }\end{array}$ \\
\hline 5. Positive affect & $\begin{array}{l}\text { The amount and quality of positive affect, including positive mood and } \\
\text { vocalisation, and enthusiastic cooperation, anticipation and liveliness, } \\
\text { weighed against the amount and quality of negative affect and behaviour }\end{array}$ & $\begin{array}{l}1=\text { Highly negative affect } \\
2=\text { Highly negative affect }\end{array}$ \\
\hline 6. Liveliness & $\begin{array}{l}\text { The level of physical activity, independent of the nature of the activity, } \\
\text { weighting behaviour initiated by the infant spontaneously over that } \\
\text { which is in response to the mother's actions. Reflex movements and } \\
\text { those controlled by the parent (e.g. by manipulating limbs) are not included }\end{array}$ & $\begin{array}{l}1 \text { = Unlively } \\
7=\text { Extremely lively }\end{array}$ \\
\hline \multicolumn{3}{|c|}{ 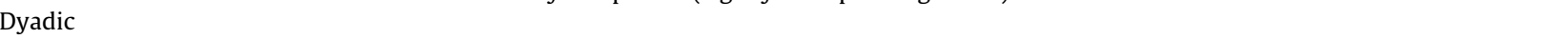 } \\
\hline 8. Intensity of engagement & $\begin{array}{l}\text { The intensity (not quantity) of mutual engagement, either directly or } \\
\text { through mutual focus on a third object. Intensity rates higher with level } \\
\text { of interest and positivity, and includes smiles, vocalisations, deepening } \\
\text { of interest, and peaks of infant excitement, with laughter or mirroring }\end{array}$ & $\begin{array}{l}1=\text { Almost no engagement } \\
7=\text { Very intense engagement }\end{array}$ \\
\hline
\end{tabular}

\section{References}

Baker, J. K., Messinger, D. S., Lyons, K. K., \& Grantz, C. J. (2010). A pilot study of maternal sensitivity in the context of emergent autism. Journal of Autism and Developmental Disorders, 40, 988-999.

Blazey, L., Leadbitter, K., Holt, C., \& Green, J. (2008). Attachment behaviours and parent-child interaction in pre-school autism. London, UK: International Meeting for Autism Research.

Bryson, S. E., Zwaigenbaum, L., McDermott, C., Rombough, V., \& Brian, J. (2008). The autism observation scale for infants: Scale development and reliability data. Journal of Autism and Developmental Disorders, 38, 731-738.

Cassel, T. D., Messinger, D. S., Ibanez, L. V., Haltigan, J. D., Acosta, S. I., \& Buchman, A. C. (2007). Early social and emotional communication in the infant siblings of children with autism spectrum disorders: An examination of the broad phenotype. Journal of Autism and Developmental Disorders, 37, $122-132$.

Christensen, L., Hutman, T., Rozga, A., Young, G. S., Ozonoff, S., Rogers, S. J\& h., et al. (2010). Play and developmental outcomes in infant siblings of children with autism. Journal of Autism and Developmental Disorders, 40, 946-957.

Cielinski, K. L., Vaughn, B. E., Seifer, R., \& Contreras, J. (1995). Relations among sustained engagement during play, quality of play, and mother-child interaction in samples of children with Down Syndrome and normal developing toddlers. Infant Behavior and Development, 18, $163-176$.

Clifford, S. M., \& Dissanayake, C. (2008). The early development of joint attention in infants with autism disorder using home video observations and parental interview. Journal of Autism and Developmental Disorders, 38, 791-805.

Dalton, K. M., Nacewicz, B. M., Alexander, A. L., \& Davidson, R. J. (2007). Gaze-fixation, brain activation, and amygdala volume in unaffected siblings of individuals with autism. Biological Psychiatry, 61, 512-552.

Dawson, G. (2008). Early behavioural intervention, brain plasticity, and the prevention of autism spectrum disorder. Development and Psychopathology, 20, 775803.

de Haan, M., Belsky, J., Reid, V., Volein, A., \& Johnson, M. H. (2004). Maternal personality and infants' neural and visual responsivity to facial expressions of emotion. Journal of Child Psychology and Psychiatry, 45, 1209-1218.

Doussard-Roosevelt, J. A., Joe, C. M., Bazhenova, O. V., \& Porges, S. W. (2003). Mother-child interaction in autistic and nonautistic children: Characteristics of maternal approach behaviours and child social responses. Development and Psychopathology, 15, 277-295.

Elsabbagh, M., \& Johnson, M. (2007). Infancy and autism: Progress, prospects, and challenge. Progress in Brain Research, 164, 355-382.

Elsabbagh, M., \& Johnson, M. H. (2010). Getting answers from babies about autism. Trends in Cognitive Science, $14,81-87$.

Esposito, G., \& Venuti, P. (2009). Comparative analysis of crying in children with autism, developmental delays, and typical development. Focus on Autism and Other Developmental Disabilities, 24, 240-247.

Feldman, R., \& Greenbaum, C. W. (1997). Affect regulation and synchrony in mother-infant play as precursors to the development of symbolic competence. Infant Mental Health Journal, 18, 4-23.

Garon, N., Bryson, S. E., Zwaigenbaum, L., Smith, I. M., Brian, J., Roberts, W., et al. (2009). Temperament and its relationship to autistic symptoms in a high-risk infant sib cohort. Journal of Abnormal Child Psychology, 37, 59-78.

Goldberg, W. A., Jarvis, K. L., Osann, K., Laulhere, T. M., Straub, C., Thomas, E., et al. (2005). Brief report: Early social communication behaviours in the younger siblings of children with autism. Journal of Autism and Developmental Disorders, 35, 657-664.

Goodman, R., Ford, T., Richards, H., Gatward, R., \& Meltzer, H. (2000). The Development and Well-Being Assessment: Description and initial validation of an integrated assessment of child and adolescent psychopathology. Journal of Child Psychology and Psychiatry, 41, 645-655.

Green, J., \& Dunn, G. (2008). Using intervention trials in developmental psychiatry to illuminate basic science. British Journal of Psychiatry, $192,323-325$.

Green, J., Charman, T., McConachie, H., Aldred, C., Slonims, V., Howlin, H., et al. (2010). Parent-mediated communication-focused treatment in children with autism (PACT): A randomised controlled trial. The Lancet, 375, 2152-2160.

Hamlyn-Wright, S., Draghi-Lorenz, R., \& Ellis, J. (2007). Locus of control fails to mediate between stress and anxiety and depression in parents of children with a developmental disorder. Autism, 11, 489-501.

Irwin, S. A., Swain, R. A., Christmon, C. A., Chakravarti, A., Weiler, I. J., \& Greenough, W. T. (2000). Evidence for altered fragile-X mental retardation protein expression in response to behavioral stimulation. Neurobiology of Learning and Memory, 74, 87-93.

Kuhn, J. C., \& Carter, A. S. (2006). Maternal self-efficacy and associated parenting cognitions among mothers of children with autism. American Journal of Orthopsychiatry, 76, 564-575.

Landa, R. J., \& Garrett-Mayer, E. (2006). Development in infants with autism spectrum disorders: A prospective study. Journal of Child Psychology and Psychiatry, 47, $629-638$.

Landa, R. J., Holman, K. C., \& Garrett-Mayer, E. (2007). Social and communication development in toddlers with early and later diagnosis of autism spectrum disorders. Archives of General Psychiatry, 64, 853-864. 
Leonard, H. C., Elsabbagh, M., Hilla, E. L., \& The BASIS team. Early and persistent motor delay in Autism Spectrum Disorder: A prospective study of at-risk infants, submitted for publication.

Lemanek, K. L., Stone, W. L., \& Fishel, P. T. (1993). Parent-child interactions in handicapped preschoolers: The relation between parent behaviors and compliance. Journal of Clinical Child Psychology, 22, 68-77.

Landry, S. H., \& Chapieski, M. L. (1989). Joint attention and infant toy exploration: Effects of Down Syndrome and prematurity. Child Development, 60, 103-118.

Lussier, B. J., Crimmins, D. B., \& Alberti, D. (1994). Effect of three adult interaction styles on infant engagement. Journal of Early Intervention, 18, 12-24.

Marfo, K. (1990). Maternal directiveness in interactions with mentally handicapped children: An analytical commentary. Journal of Child Psychology and Psychiatry, $31,531-549$.

Matias, C. S. F. (2006). Direct Observations of parent-child Interaction based on Attachment Theory. PhD thesis. London: Institute of Psychiatry, King's College.

Merin, N., Young, G. S., Ozonoff, S., \& Rogers, S. J. (2007). Visual fixation patterns during reciprocal social interaction distinguished a subgroup of 6-month-old infants at-risk for autism from comparison infants. Journal of Autism and Developmental Disorders, 37, 108-121.

Mesman, J. (2010). Maternal responsiveness to infants: Comparing micro-level and macro-level measures. Attachment and Human Development, 12, 149-155.

Mitchell, S., Brian, J., Zwaigenbaum, L., Roberts, W., Szatmari, P., Smith, I., et al. (2006). Early language and communication development of infants later diagnosed with autism spectrum disorder. Developmental and Behavioral Pediatrics, 27, 69-78.

Murray, L., Fiori-Cowley, A., Hooper, R., \& Cooper, P. J. (1996). The impact of postnatal depression and associated adversity on early mother-infant interactions and later infant outcome. Child Development, 67, 2512-2526.

Nassan El-Ghoroury, N., \& Romanczyk, G. (1999). Play interactions of family members towards children with autism. Journal of Autism and Developmental Disorders, 29, 249-258.

NICHD Early Child Care Research Network. (2001). Child care and children's peer interaction at 24 and 36 months: The NICHD study of early child care. Child Development, 72, 1478-1500.

Osterling, J. A., \& Dawson, G. (1994). Early recognition of children with autism: A study of first birthday home videotapes. Journal of Autism and Developmental Disorders, 24, 247-257.

Pastor, D. L. (1981). The quality of mother-infant attachment and its relationship to toddlers' initial sociability with peers. Developmental Psychology, 17, 326-335.

Piven, J., Palmer, P., Jacobi, D., Childress, D., \& Arndt, S. (1997). Broader autism phenotype: Evidence from a family history study of multiple-incidence autism families. American Journal of Psychiatry, 154, 185-190.

Poon, K. K., Watson, L. R., Baranek, G. T., \& Poe, M. D. (2011). To what extent do joint attention, imitation, and object play behaviors in infancy predict later communication and intellectual functioning in ASD? Journal of Autism and Developmental Disorders doi:10.1007/s10803-011-1349.

Rogers, S. J. (2009). What are infant siblings teaching us about autism in infancy? Autism Research, 2, 125-137.

Rozga, A., Hutman, T., Young, G. S., Rogers, S. J., Ozonoff, S., Dapretto, M., et al. (2011). Behavioral profiles of affected and unaffected siblings of children with autism: Contribution of measures of mother-infant interaction and nonverbal communication. Journal of Autism and Developmental Disorders, 41, 287-301

Rutter, M., Bailey, A., \& Lord, C. (2003). Social communication questionnaire. L.A. WPS.

Saint-Georges, C., Mahdhaoui, A., Chetouani, M., Cassel, R. S., Laznik, M.-C., Apicella, F., et al. (2011). Do parents recognize autistic deviant behavior long before diagnosis? Taking into account interaction using computational methods. PLOS One, 6, 1-13.

Siller, M., \& Sigman, M. (2002). The behaviors of parents of children with autism predict the subsequent development of their children's communication. Journal of Autism and Developmental Disorders, 32, 77-89.

Siller, M., \& Sigman, M. (2008). Modeling longitudinal change in the language abilities of children with autism: Parent behaviors and child characteristics as predictors of change. Developmental Psychology, 44, 1691-1704.

Slomins, V., \& McConachie, H. (2006). Analysis of mother-infant interaction in infants with Down syndrome and typically developing infants. American Journal on Mental Retardation, 111, 273-289.

Stone, W. L., McMahon, C. R., Yoder, P. J., \& Walden, T. A. (2007). Early social-communicative and cognitive development of younger siblings of children with autism spectrum disorders. Archives of Pediatrics and Adolescent Medicine, 161, 384-390.

Tomanik, S., Harris, G. E., \& Hawkins, J. (2004). The relationship between behaviors exhibited by children with autism and maternal stress. Journal of Intellectual and Developmental Disabilities, 29, 16-26.

Trevarthen, C., \& Aitken, K. J. (2001). Infant intersubjectivity: Theory, and clinical applications. Journal of Child Psychology and Psychiatry, 42, 3-48.

Tronick, E. Z., Als, H., Adamson, L., Wise, S., \& Brazelton, T. B. (1978). The infant's response to entrapment between contradictory messages in face-to-face interaction. Journal of the American Academy of Child \&' Adolescent Psychiatry, 17, 1-13.

Wallace, K. S., \& Rogers, S. J. (2010). Intervening in infancy: Implications for autism spectrum disorders. Journal of Child Psychology and Psychiatry, 51, 1300-1320.

Yirmiya, N., \& Charman, T. (2010). The prodrome of autism: Early behavioral and biological signs, regression, peri- and post-natal development and genetics. Journal of Child Psychology and Psychiatry, 51, 432-458.

Yirmiya, N., Gamliel, I., Pilowsky, T., Feldman, R., Baron-Cohen, S., \& Sigman, M. (2006). The development of siblings of children with autism at 4 and 14 months: Social engagement, communication, and cognition. Journal of Child Psychology and Psychiatry, 47, 511-523.

Zwaigenbaum, L., Bryson, S., Rogers, T., Roberts, W., Brian, J., \& Szatmari, P. (2005). Behavioral manifestations of autism in the first year of life. International Journal of Developmental Neuroscience, 23, 143-152. 